\title{
A prospective study on neonatal outcome of preterm births and associated factors in a South Indian tertiary hospital setting
}

\author{
Tinu Philip ${ }^{1}$, Pramod Thomas ${ }^{2 *}$
}

\begin{abstract}
${ }^{1}$ Department of Obstetrics and Gynecology, ${ }^{2}$ Department of Community Medicine, Believers Church Medical College Hospital, Tiruvalla, Kerala, India
\end{abstract}

Received: 13 November 2018

Accepted: 19 November 2018

\section{*Correspondence:}

Dr. Pramod Thomas,

E-mail: tinuphilipdr@gmail.com

Copyright: $\odot$ the author(s), publisher and licensee Medip Academy. This is an open-access article distributed under the terms of the Creative Commons Attribution Non-Commercial License, which permits unrestricted non-commercial use, distribution, and reproduction in any medium, provided the original work is properly cited.

\section{ABSTRACT}

Background: In spite of the manifold advances in obstetric care, preterm births are still a nightmare for the obstetrician, the pregnant women and her family. The present study aims to study the neonatal outcome in preterm births and its association with sociodemographic, medical and obstetric risk factors.

Methods: A prospective observational study done in the Department of Obstetrics and Gynecology in a tertiary level hospital in South India for a period of two years.

Results: Majority of the preterm births in this study were in 32-34 weeks which accounted for $53.43 \%$ of the preterm births. The immediate neonatal mortality in this study is around $18.25 \%$. The partner's occupation, the booking status of the mother is strongly associated with preterm births. Pregnancies above the third order were also significantly associated with risk of preterm birth. $44.8 \%$ of preterm births are idiopathic, $18.64 \%$ have hypertension complicating pregnancy, $14.4 \%$ were multiple pregnancies. Neonatal mortality was $30.8 \%$ in pregnancies with hypertension complicating pregnancies. Most common complication of prematurity in present study was Hyaline Membrane Disease and pneumonia.

Conclusions: Preventive measures, early identification of risk factors and strengthening the referral system will improve the outcome of the preterm babies and to ensure a positive pregnancy outcome to all pregnant women.

Keywords: Fetal anomalies, Hypertension, Neonatal outcome, Preterm birth, Spontaneous preterm birth

\section{INTRODUCTION}

Preterm birth is a major contributor of neonatal mortality and morbidity. The World Health Organization defines preterm birth as any birth before 37 completed weeks of gestation or less than 259 days since the first day of woman's Last Menstrual Period (LMP).

Every year, an estimated 15 million babies are born preterm (before 37 completed weeks of gestation), and this number is rising. ${ }^{1}$ Across 184 countries, the rate of preterm birth ranges from 5\% to $18 \%$ of babies born. In India, out of 27 million babies born every year (2010 data), 3.5 million babies born are premature. ${ }^{1}$ About two thirds of these preterm births occur between 34 and 37 weeks. The increasing trend of preterm birth can be attributed to the better dating facilities, better reporting of preterm births, advanced infertility treatments leading to increased rates of multiple pregnancies, and changes in obstetric practices such as more caesarean births before term.

Preterm birth complications are the leading cause of death among children less than 5 years of age, responsible for approximately 1 million deaths in $2015 .^{2}$ It contributes to $75 \%$ of all perinatal deaths. ${ }^{3} 85 \%$ of neonatal deaths occur in preterm babies. Approximately three-fourths of perinatal deaths occur in fetuses that are delivered at $<37$ weeks, and about $40 \%$ of these deaths occur in those delivered at $<32$ weeks. Three-quarters of 
these deaths could be prevented with current, costeffective interventions. There is a dramatic difference in survival of premature babies depending on where they are born. For example, more than $90 \%$ of extremely preterm babies (less than 28 weeks) born in low-income countries die within the first few days of life; yet less than $10 \%$ of extremely preterm babies die in high-income settings. ${ }^{1}$ In addition to its contribution to mortality, preterm birth accounts for half of the long term neurological morbidity in childhood such as increased risk of cerebral palsy, impaired learning, and visual disorders and an increased risk of chronic disease in adulthood. ${ }^{4}$ The economic cost of preterm birth is high in terms of neonatal intensive care and ongoing health care and educational needs of the babies who were 'born too soon.'

A wide spectrum of causes and demographic factors has been implicated in the birth of preterm infants but the precise etiology is still not known. The mediating factors that connect the underlying epidemiological or medical risk factors to preterm birth are poorly understood.

Very often, the diagnosis of preterm labour is itself difficult and most often made at an advanced stage of labour. Identification of the associated risk factors for the poor perinatal outcome of preterm births might define a population useful for studying specific interventions and might also provide important insights into mechanisms leading to preterm birth.

Implementation of the WHO recommendations of 2015 to improve the outcome of preterm birth like use of corticosteroids, tocolytics, and magnesium sulfate for neuroprotection and special care of the preterm neonate is essential for neonatal survival. $^{5}$

Despite advances in perinatal medicine in recent decades, preterm delivery continues to pose a challenge to both the obstetrician and the neonatologist.

Keeping the above scenario in mind the present study was undertaken to analyse the different demographic and obstetric risk factors which influence the neonatal outcome of preterm births and to assess the neonatal mortality and morbidity in preterm births.

\section{METHODS}

The present prospective observational study was conducted in the Department of Obstetrics and Gynaecology Labour Ward in a South Indian tertiary care government hospital.

Ethical permission was obtained from the institutional review board and the duration of the study was two years.

Participants represented various parts of South India and were enrolled with consecutive sampling technique. Eligible participants were approached in the labour ward and Informed consent was obtained before enrolling in to the study.

\section{Inclusion criteria}

- Cases of established preterm labour (both spontaneous and induced preterm labors) which presented to the labour ward. ${ }^{6}$

\section{Exclusion criteria}

- Pregnancies before 26 weeks and beyond 37 completed weeks; pregnant women with the last menstrual period not known, or pregnant women without an early ultrasound report ( $<24$ weeks) available and Intrauterine foetal demises.

Gestational age assessment was done at the time of admission. In patients who had reliable dates, gestational age was calculated from their last menstrual period. In those without reliable dates, an early ultrasound $(<24 \mathrm{wks}$ as recommended by WHO) was used to confirm the gestational age. Gestational age of 26 weeks was taken as the lower limit for viability taking into account the NICU facilities of the hospital. Multiple pregnancy was confirmed by clinical and ultrasound examinations. The booking status (booked or unbooked) of the patient was defined as at least 4 contacts with the antenatal care giver. $^{7}$

An unstructured questionnaire was used to assess the demographic, obstetric and medical history of the patients. All patients were subjected to at least one ultrasonography examination in the labour room to assess the gestational age and liquor status. Birth weights of the neonates were assessed using the electronic weighing scale.

The Apgar score was assessed by the neonatologist and the data was collected from the Neonatal Intensive Care Unit (NICU) records. Sepsis, Hyaline membrane disease (HMD) and Hyperbilirubinemia were recorded from the NICU records.

Postnatal mortality (alive, still born, neonatal death) and morbidity (Apgar scores, birth weight of the baby, immediate neonatal complications like HMD, hyperbilirubinemia, sepsis) of the preterm birth were the outcome measures analysed in the study.

Maternal age, Gestational Age, occupation of the partner, parity, pregnancy order, previous pregnancy outcomes, presence of any medical (hypertensive disorders, diabetes, anaemia, heart disease, maternal infections) and obstetric risk factors (foetal anomalies, Preterm Premature rupture of membranes, placenta praevia, abruption placenta) during this pregnancy period were considered as explanatory variables for the outcome measures. Gestational age was classified as 26-32 weeks 
(early preterm), 32-34 weeks (preterm) and 34-37 weeks (late preterm).

The study extended for a period of two years and participants were enrolled as required for the study. Data was entered into excel and doubled checked for eliminating the data entry errors. To maintain the confidentiality, data was entered anonymously using separate codes and personal identifications were avoided.

\section{Statistical analysis}

Descriptive measures were assessed on postnatal outcome and various sociodemographic, medical, obstetric risk factors and gestational age. Bivariate analyses were conducted using chi-square test to find if any associations existed between outcome measures and various independent variables.

\section{RESULTS}

Out of the 1078 preterm births, pregnancies with Gestational age <32 weeks account for $8.53 \%, 32-34$ weeks account for $53.43 \%$ and $>34$ weeks account for $38.03 \%$ of the preterm births (Figure 1).

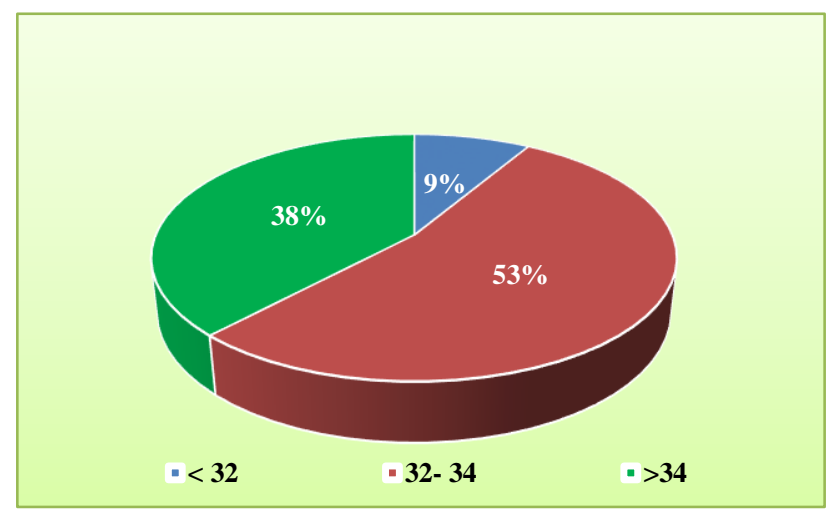

Figure 1: Distribution of preterm birth according to gestational age.

The immediate neonatal mortality in the study is $18.25 \%$ (Figure 2).

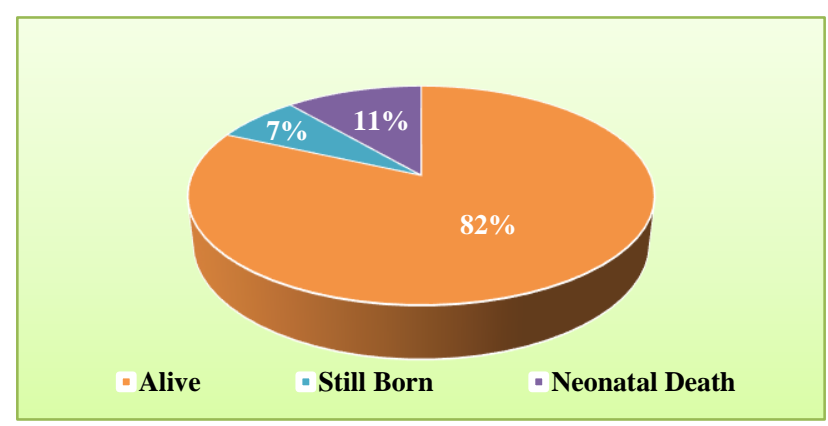

Figure 2: Distribution of preterm birth according to neonatal outcome.
This was further analysed depending on the gestational age (Figure 3).

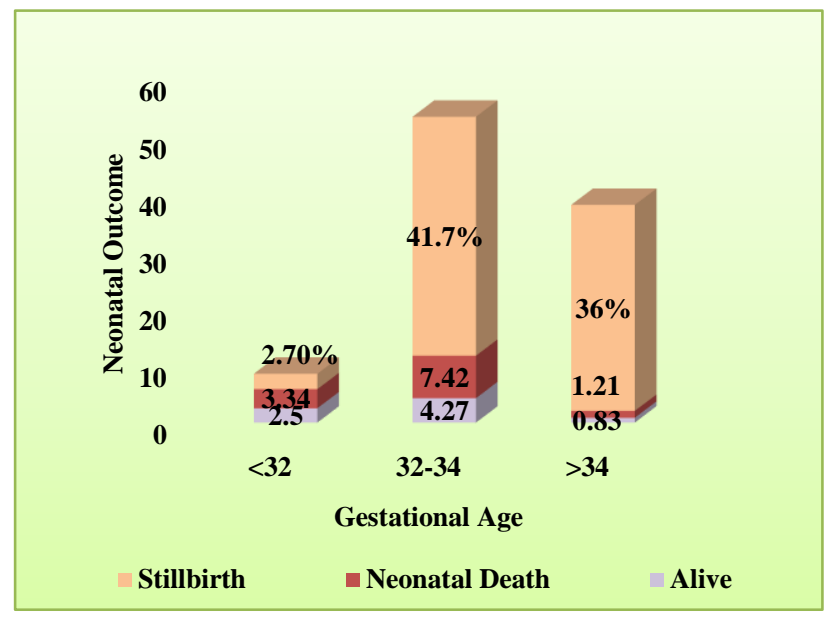

Figure 3: Distribution of neonatal outcome according to gestational age.

The maternal demographic factors were analysed for their association with the neonatal outcome in these preterm births (Table 1). There is no significant association of the maternal age to the neonatal outcome in preterm births in present study $(\mathrm{p}=0.070)$. The neonatal outcome is significantly associated with the booking status of the mother. There is a definite trend in the neonatal outcome depending on the occupation of the partner $(\mathrm{p}=0.05)$. The neonatal outcome is also significantly associated with the parity of the mother. Pregnancies above the third order are associated with higher mortality of the preterm births $(\mathrm{p}=0.032)$.

The immediate neonatal mortality is higher in pregnancies with an antecedent history of more than one preterm birth/more than one PPROM/or a combined history of one abortion with one preterm birth than a pregnancy with history of more than one abortion alone. This association is higher than in a pregnancy with no such antecedent history $(\mathrm{p}=0.004)$.

The postnatal outcome was further analysed on the basis of obstetric indication for the preterm birth. Out of the 1078 preterm births, $44.8 \%$ are idiopathic. Spontaneous preterm labour or medically indicated preterm terminations of pregnancy in hypertensive disorders contribute $18.64 \%$ of the preterm birth. Multiple pregnancies account for $14.4 \%$ of the preterm birth, PPROM in $7.14 \%$ of cases.

Maternal infections account for $2.04 \%$ and foetal anomalies account for $2.74 \%$ of cases. (table 2) $30.8 \%$ of preterm labour with hypertension complicating pregnancies has an immediate postnatal mortality. Pregnancies with foetal anomalies have a high immediate neonatal mortality of $51.4 \%$. Pregnancies complicated by maternal infections (chickenpox, fever, jaundice, UTI, sepsis) have $31.8 \%$ poor neonatal outcome. $58.5 \%$ of 
extremely low birth weight babies ( $<1 \mathrm{~kg}$-ELBW) have an immediate neonatal mortality compared to only $13.3 \%$ of low birth weight babies $(<2.5 \mathrm{~kg}-\mathrm{LBW})$ Apgar scores at 1 minute and 5 minutes was studied, and both were associated with the immediate neonatal outcome.

Table 1: Association of neonatal outcome in preterm deliveries with maternal demographical and obstetric factors.

\begin{tabular}{|c|c|c|c|c|c|c|c|c|}
\hline \multirow{3}{*}{$\begin{array}{l}\text { Demographic and } \\
\text { obstetric factors }\end{array}$} & \multicolumn{6}{|c|}{ Immediate neonatal outcome } & \multirow{3}{*}{$\begin{array}{l}\text { Chi- } \\
\text { square } \\
\text { value }\end{array}$} & \multirow{3}{*}{ p- value } \\
\hline & \multicolumn{2}{|l|}{ Still born } & \multicolumn{2}{|c|}{ Neonatal Death } & \multicolumn{2}{|l|}{ Alive } & & \\
\hline & Frequency & $(\%)$ & Frequency & $(\%)$ & Frequency & $(\%)$ & & \\
\hline \multicolumn{9}{|l|}{ Maternal Age } \\
\hline$\leq 19$ years & 4 & 5.1 & 7 & 8.9 & 68 & 86.1 & \multirow{4}{*}{12.976} & \multirow{4}{*}{$\mathrm{p}=0.070$} \\
\hline $20-24$ years & 45 & 8.0 & 57 & 10.1 & 461 & 81.9 & & \\
\hline $25-29$ years & 23 & 6.4 & 53 & 14.7 & 285 & 78.9 & & \\
\hline$\geq 30$ years & 10 & 13.3 & 12 & 16.0 & 53 & 70.7 & & \\
\hline \multicolumn{9}{|l|}{ Father's Occupation } \\
\hline Business & 5 & 6.4 & 15 & 19.2 & 58 & 74.7 & \multirow{4}{*}{12.315} & \multirow{4}{*}{$\mathrm{p}=0.05$} \\
\hline Electrician & 10 & 7.7 & 11 & 8.5 & 109 & 83.8 & & \\
\hline $\mathrm{PC}$ & 3 & 4.1 & 3 & 4.1 & 68 & 91.9 & & \\
\hline Mason/coolie & 64 & 8.0 & 100 & 12.6 & 632 & 79.4 & & \\
\hline \multicolumn{9}{|l|}{ Booking Status } \\
\hline Booked & 29 & 5.6 & 57 & 11.1 & 428 & 83.3 & \multirow{2}{*}{6.603} & \multirow{2}{*}{$\mathrm{p}=0.05$} \\
\hline Unbooked & 53 & 9.4 & 72 & 12.8 & 439 & 77.8 & & \\
\hline \multicolumn{9}{|l|}{ Pregnancy order } \\
\hline Primi & 44 & 7.1 & 67 & 10.8 & 511 & 82.2 & \multirow{4}{*}{13.764} & \multirow{4}{*}{$\mathrm{p}=0.032$} \\
\hline $\mathrm{G} 2$ & 18 & 5.8 & 45 & 14.5 & 247 & 79.7 & & \\
\hline G3 & 16 & 14.2 & 11 & 9.7 & 86 & 76.1 & & \\
\hline$\geq \mathrm{G} 4$ & 4 & 12.1 & 6 & 18.2 & 23 & 69.7 & & \\
\hline \multicolumn{9}{|l|}{ Obstetric history } \\
\hline $\begin{array}{l}\text { No abortion/no } \\
\text { preterm/no PPROM }\end{array}$ & 60 & 6.7 & 101 & 11.4 & 728 & 81.9 & \multirow{4}{*}{19.3} & \multirow{4}{*}{$\mathrm{p}=0.004$} \\
\hline One abortion & 17 & 16.8 & 14 & 13.9 & 70 & 69.3 & & \\
\hline $\begin{array}{l}>\text { One preterm/ > one } \\
\text { abortion }\end{array}$ & 0 & 0.0 & 6 & 23.1 & 20 & 76.9 & & \\
\hline $\begin{array}{l}\text { One preterm/one } \\
\text { PPROM/one abortion + } \\
\text { one preterm }\end{array}$ & 5 & 8.1 & 8 & 12.9 & 49 & 79.0 & & \\
\hline
\end{tabular}

Table 2: Association of neonatal outcome in preterm deliveries with obstetric and medical indications.

\begin{tabular}{|l|llll|}
\hline $\begin{array}{l}\text { Obstetric and medical } \\
\text { indications }\end{array}$ & $\begin{array}{l}\text { Still born } \\
\text { frequency }\end{array}$ & $\begin{array}{l}\text { Im) } \\
\text { Neonatal death } \\
\text { frequency }(\%)\end{array}$ & $\begin{array}{l}\text { Alive } \\
\text { frequency (\%) }\end{array}$ & $\begin{array}{l}\text { Total births } \\
\text { frequency }(\%)\end{array}$ \\
\hline Hypertension & $27(13.4)$ & $35(17.4)$ & $139(69.2)$ & $201(18.64)$ \\
\hline Multiple pregnancy & $5(3.2)$ & $34(21.8)$ & $117(75.0)$ & $156(14.4)$ \\
\hline Fetal anomaly & $6(20.7)$ & $6(20.7)$ & $17(58.6)$ & $29(2.74)$ \\
\hline Infections & $3(13.6)$ & $4(18.2)$ & $15(68.2)$ & $22(2.04)$ \\
\hline Placental abruption/praevia & $21(23.6)$ & $15(16.9)$ & $53(59.6)$ & $89(8.28)$ \\
\hline PPROM & $1(1.3)$ & $6(7.8)$ & $70(90.8)$ & $77(7.14)$ \\
\hline Heart disease/diabetes & $2(9.5)$ & $3(14.3)$ & $16(76.2)$ & $21(1.96)$ \\
\hline Idiopathic & $17(3.5)$ & $26(5.4)$ & $440(91.1)$ & $483(44.8)$ \\
\hline
\end{tabular}

Low Apgar scores are associated with poor outcome and higher Apgar scores are associated with better neonatal outcome. The most common complication leading to death in the immediate neonatal period was Hyaline
Membrane Disease (HMD) and pneumonia seen in 36.7\% of the deaths. Sepsis was seen in $20.31 \%$ cases and birth asphyxia in $13.28 \%$ of the preterm deaths in the immediate neonatal period. HMD was most common in the extremely low birth weight babies (ELBW). HMD is 
seen in $26.4 \%$ of the ELBW deaths whereas was seen in only $7.4 \%$ of deaths in LBW babies.

\section{DISCUSSION}

Prematurity poses a heavy burden of death and disability to the neonate, pain and suffering to the concerned families. In this study, a systematic analysis was done to find the risk factors associated with immediate neonatal mortality of the preterm births. Present study showed that majority of the preterm births belong to the early preterm births (32-34 weeks). A similar finding was reported by the Institute of Medicine (US). 8 We found no association of maternal age to the poor neonatal outcome. This differs from the previous studies which show an association of advanced maternal age. This may be due to the less number of cases above 30 years in our sample. ${ }^{9}$ In present study, the booking status of the mother is a significant determinant for the neonatal outcome. We used the 4 visit WHO ANC model for present study. Several studies have showed that poor utilization of antenatal services is associated with poor pregnancy outcome in preterm births. ${ }^{10,11}$ In present study, multiparity above the third order was significantly associated with poor neonatal outcome in preterm birth. Several other studies also have shown that multiparity is a risk factor for preterm birth. ${ }^{12,13}$

The previous obstetric history is a significant determinant of the perinatal outcome in preterm births. Several studies have showed that the risk of preterm birth is higher in patients with a history of abortion or a history of preterm birth. Studies have shown significant correlation between the number of previous abortions and the risk of preterm birth. ${ }^{14,15}$ There is a $32 \%$ increased risk of preterm delivery after 3 preterm deliveries compared to $15 \%$ with history of one preterm delivery according to Carr-Hill. ${ }^{16}$, ${ }^{17}$ In this study, previous history of one preterm birth /one PPROM or a history of preterm birth combined with a history of one abortion had a higher risk of perinatal mortality than pregnancies with no antecedent history. Hence the identification of pregnancies with risk factors at the primary health centre levels and timely referral can modify the outcome of preterm births. $44.8 \%$ of the preterm births in present study were unexplained. Similar observation has been reported by Beck et al. ${ }^{18}$ In present study, hypertensive disorders which were associated with $18.64 \%$ of preterm birth was the most important medical risk factor. This is comparable to the studies by Fernades et al at $21.07 \%$ but higher than the studies of Shreshta et al at $13.3 \%$ and Taskeen et al at $14 \% .{ }^{19}$ Hypertensive disorders are also the highest contributor to the perinatal mortality. The prematurity in hypertensive disorders is both due to spontaneous preterm as well as medically indicated termination of pregnancy. Identification and institution of early treatment in hypertensive disorders, referral to obstetric units with level 3 NICU facilities will reduce the prematurity associated with hypertensive disorders. The incidence of foetal anomalies was high in this study $(2.74 \%)$ with more than half of them dying in the immediate neonatal period. Other studies have also reported high preterm births in babies with foetal anomalies. $^{20,21}$ This may be because the centre of this study is a referral centre for far flung areas with low educational standards and poor socioeconomic status where the implementation of diagnostic facilities in routine antenatal care is poor. Hence these patients are referred very late in pregnancy. Empowering the primary antenatal care setups in low resource countries with better diagnostic facilities and enforcing the WHO guideline of at least one ultrasound before 24 weeks will help to identify the lethal/nonlethal foetal anomalies, thereby helping to reduce the burden on the system. Infections and vaginosis are well-known risk factors for preterm birth. In a study, presence of bacterial vaginosis at 28 weeks gestation was associated with an increased risk of spontaneous preterm birth. ${ }^{22}$ Infection contributed to only $2.04 \%$ of preterm births in present study. Though a small contributor, these are preventable and hence prompt recognition of infections and early institution of the right treatment needs to be an integral part of antenatal care.

Apgar scores at $1 \mathrm{~min}$ and $5 \mathrm{~min}$ are associated with neonatal mortality in preterm babies in this study. It has also been previously shown that the most evident risk factor for Apgar scores <7 is preterm birth. ${ }^{23}$ Lee et al has studied that Low Apgar score was associated with increased mortality in premature neonates, including those at 24 to 28 weeks gestational age, and may be a useful tool for clinicians in assessing prognosis and for researchers as a risk prediction variable. ${ }^{24}$ Mortality in present study was highest in ELBW followed by LBW as shown in previous studies also. RDS and sepsis were major causes of death in ELBW and VLBW babies according to D. Manikyamba et al. whereas, sepsis and birth asphyxia were major causes of death in LBW babies. $^{25}$ In present study HMD and sepsis were the major cause of death in both ELBW and LBW babies which is in agreement with the studies done by Cupen et al which shows sepsis/infections and pneumonia as a cause of death in $31.3 \% .{ }^{26}$ The strength of present study is the relatively large sample size. The scope of the study is limited to only the immediate neonatal outcome (within 7 days of birth). Further studies will be needed to look into the morbidity and mortality of these babies at one year and also the long-term morbidities. The neurological morbidity associated with preterm births has not been studied as it was outside the scope of the study. The study is also limited to a single tertiary centre.

\section{CONCLUSION}

In spite of the advances made in antenatal care and neonatal services, preterm birth still remains an economic as well as emotional burden to the families. In low resource settings empowering the primary care providers with adequate knowledge with emphasis on prevention of preterm births, identification of risk factors, avoiding late referrals will benefit. Strengthening the referral system to make sure that high risk patients are managed in tertiary 
obstetric units with level 3 NICU facilities will improve the neonatal outcome of these babies who are" Born too Soon" to a great extent. Further studies will have to be done to evaluate the implementation of the WHO 2016 ANC guidelines which recommend 8 contacts to reduce the perinatal mortality and morbidity instead of the focused antenatal care of 4 visit ANC model.

\section{ACKNOWLEDGMENTS}

Authors would like to thank Prof. Dr. Madhini, and Prof. Dr. Radhabhai, Department of Obsterics and Gynecology for the valuable suggestions and guidance.

\section{Funding: No funding sources}

Conflict of interest: None declared

Ethical approval: The study was approved by the Institutional Ethics Committee

\section{REFERENCES}

1. National health portal of India: May 23,2016 Available at http://ww.nhp.gov.in

2. Liu L, Oza S, Hogan D, Chu Y, Perin J, Zhu J, et al. Global, regional, and national causes of under-5 mortality in 2000-15: an updated systematic analysis with implications for the Sustainable Development Goals. Lancet. 2016;388(10063):3027-35

3. Hack M, Fanaroff AA. Outcomes of extremely immature infants - a perinatal medicine. N Engl JMed. 1993;329:1649-1650.

4. Shrestha S, Dangol SS, Shrestha M, Shrestha RP. Outcome of preterm babies and associated risk factors in a hospital. J Nepal Med Asso. 2010;50(180).

5. Iams JD, Romero R, Culhane JF, Goldenberg RL. Primary, secondary, and tertiary interventions to reduce the morbidity and mortality of preterm birth. Lancet. 2008;371(9607):164-75.

6. National Institute of Health and Care Excellence Guidelines: November 2015: Available at https://www.nice.org.uk

7. WHO antenatal care randomised trial: manual for the implementation of the new model.Geneva:World Health Organisation :2002

8. Institute of Medicine (US) Committee on Understanding Premature Birth and Assuring Healthy Outcomes: Behrman RE, Butler AS, editors. Preterm Birth: Causes, Consequences, and Prevention. Washington (DC): National Academies Press (US); 2007. Summary. Available at: https://www.ncbi.nlm.nih.gov/books/NBK11350/.

9. Fuchs F, Monet B, Ducruet T, Chaillet N, Audibert F. Effect of maternal age on the risk of preterm birth: A large cohort study. Gutman J, ed. PLoS ONE. 2018;13(1):e0191002.

10. Halimi Asl AA, Safari S, Parvareshi HM. Epidemiology and Related Risk Factors of Preterm Labor as an obstetrics emergency. Emerg (Tehran). 2017;5(1):e3.

11. Heaman M, Kingston D, Chalmers B, Sauve R, Lee L, Young D. Risk Factors for Preterm Birth and Small-for- gestational-age Births among Canadian Women. Paediat Perinat Epidemiol. 2013;27(1):54-61

12. Shetty MB, Krupa BM, Malyala M, Swarup A, Pathadan DS, Pocha S. Preterm birth: associated risk factors and outcome in tertiary care center. Int $\mathrm{J}$ Reproduct, Contracep, Obstet Gynecol. 2017;6(8):3271-4.

13. Prakash SA, Rasquinha S, Rajaratnam A. Analysis of Risk Factors and Outcome of Preterm Labor. Int J Eng Sci. 2016;2602

14. Shreshta S, Dangol SS, Shreshta M, Shreshta RPB. Outcome of preterm babies and associated risk factors in a hospital. J Nepal Med Assoc. 2010;50(180):286-90.

15. Taskeen R. Preterm delivery. A major predictor of perinatal morbidity and mortality. JPMI. 2006;20(3):279-83.

16. Pandey K, Bhagoliwal A, Gupta N, Katiyar G. Predictive value of various risk factors for preterm labour. J Obstet Gynaecol India. 2010;60(2):141-5.

17. Carr-Hill RA, Hall MH.The repetition of spontaneous preterm labour. Br J Obstet Gynecol. 1985;92(9):921-8.

18. Beck S, Wojdyla D, Say L, Betran AP, Merialdi M, Requejo JH et al. The worldwide incidence of preterm birth: a systematic review of maternal mortality and morbidity. Bulletin of the World Health Organization. 2010;88(1):31-8.

19. Fernandes SF, Chandra S. A study of risk factors for preterm labour. Int J Reprod Contracept Obstet Gynecol 2015;4(5):1306-12

20. Kase JS,Visintainer P. The relationship between congenital malformations and preterm birth. J Perinat Med. 2007;35(6):538-42.

21. Victoria B, Michelle M, Kristin G, Teresa S, Gonzalez VJ, Mary N. The Risk of Preterm Birth in Pregnancies with Fetal Anomalies. Obstet Gynecol. 2017;129(5):176S

22. Meis PJ, Goldenberg RL, Mercer B, Moawad A, Das A, McNellis D, et al. The preterm prediction study: significance of vaginal infections. Am J Obstetrics Gynaecol. 1995;173(4):1231-5.

23. Svenvik M, Brudin L, Blomberg M. Preterm birth: a prominent risk factor for low Apgar scores. BioMed research international. 2015;2015.

24. Lee HC, Subeh M, Gould JB. Low Apgar score and mortality in extremely preterm neonates born in the United States. Acta Paediatrica. 2010;99(12):1785-9.

25. Manikyamba D, Madhavi N, Prasad AK, Padmavati IV A. Morbidity and mortality of LBW Babies and their growth and neurodevelopment outcome at 1 yearNICU, Government General Hospital, Kakinada. Scholars J Appl Med Sci. 2015;3(4B):1721-5.

26. Cupen K, Barran A, Singh V, Dialsingh I. Risk factors associated with preterm neonatal mortality: A case study using data from Mt. Hope Women's Hospital in Trinidad and Tobago. Children. 2017;4(12):108.

Cite this article as: Philip T, Thomas P. A prospective study on neonatal outcome of preterm births and associated factors in a South Indian tertiary hospital setting. Int J Reprod Contracept Obstet Gynecol 2018;7:4827-32. 